\title{
Uma proposta para o ensino de probabilidades utilizando jogos e materiais manipuláveis
}

\author{
Thallia Aline Ramos (D) Glaucia Maria Bressan (D)
}

\section{Resumo}

O objetivo deste trabalho é apresentar uma discussão da aplicação de uma proposta de oficina com jogos e materiais manipuláveis, que podem auxiliar os alunos na aprendizagem do conteúdo de Probabilidade, além de proporcionar uma oportunidade para o desenvolvimento de habilidades diversas do aluno, por meio de atividades lúdicas. A atividade proposta foi aplicada no terceiro ano B e C do Ensino Médio do Colégio Estadual Cyriaco Russo de Bandeirantes - PR, como parte das atividades do Estágio Supervisionado do curso de Licenciatura em Matemática na Universidade Tecnológica Federal do Paraná - UTFPR, com o intuito de promover ensino aprendizagem para os discentes e desenvolver a compreensão com base em jogos na da sala de aula. Dessa forma, por meio da atividade proposta, é possível promover uma oportunidade para os alunos apresentarem melhor compreensão do conteúdo apresentado.

Palavras-chave: Ensino de Probabilidade; Material manipulável; Ensino-aprendizagem; Jogo

\begin{abstract}
The objective of this paper is to present a discussion about the application of a workshop proposal using games and manipulable materials, which can assist students in learning the content of Probability, as well as provide an opportunity for the development of different skills of the student, through recreational activities. The proposed activity was applied in the third year B and C of High School at Colégio Estadual Cyriaco Russo from Bandeirantes - PR, as part of the Supervised Internship activities belonging to the Mathematics Degree course at Universidade Tecnológica Federal do Paraná - UTFPR, in order to promote teaching-learning for students and develop understanding based on games in the classroom. Therefore, through the proposed activity, it is possible to provide an opportunity for students to present a better understanding of the content studied.
\end{abstract}

Keywords: Probability Teaching; Manipulated material; Teaching-learning; Game

\section{Introdução}

A aplicação de jogos e materiais manipuláveis em sala de aula contribui com uma metodologia de ensino-aprendizagem lúdica, promovendo uma oportunidade de aprendizado diferenciado. Segundo Lorenzato (2006), muitos educadores de diferentes épocas foram simpatizantes do uso de 
materiais manipuláveis, pois acreditavam que sua utilização no ensino de Matemática mediaria a aprendizagem [2]. O autor também cita Comenius (1592-1670), como precursor dessa metodologia. Como afirma Moura (1992, p. 47), "ao optar pelo jogo como estratégia de ensino, o professor o faz com uma intenção: propiciar a aprendizagem [3]".

Para o ensino de matemática por meio de materiais manipuláveis, é fundamental o domínio dos conceitos pelo docente, para que as dúvidas que possam surgir ao decorrer do jogo sejam atendidas. Conforme Muniz (2010), a forma de manipular valores, realizar operações, elaborar e solucionar problemas é determinada não só pela estrutura lúdica, mas também pelos conhecimentos socioculturais que, incorporados pelas crianças, passam a fazer parte do sistema de regras dos jogos $[4]$.

Diante desse cenário, este trabalho tem como objetivo apresentar uma proposta de aplicação de um jogo para auxiliar o processo de ensino e aprendizagem do conteúdo de Probabilidade, proporcionando uma oportunidade para o desenvolvimento de habilidades diversas do aluno, por meio de atividades lúdicas. O jogo é chamado "Minitrilha ${ }^{1 "}$ e foi aplicado no terceiro ano do Ensino Médio do Colégio Estadual Cyriaco Russo de Bandeirantes - PR, como parte das atividades do Estágio Supervisionado do curso de Licenciatura em Matemática.

\section{Referencial Teórico}

Os jogos e matérias manipuláveis podem ser utilizados como instrumento para aplicação do conteúdo proposto. No caso de Probabilidade, é importante para que o professor possa analisar as dificuldades dos alunos, tirando as dúvidas durante a aplicação das atividades e mostrando-lhes como pode ser aplicado o conteúdo estudado em diversas situações. Quanto aos jogos, Silva e Martins (2000), relatam [6]:

Os materiais manipuláveis são fundamentais se pensarmos em ajudar a criança na passagem do concreto para o abstrato, na medida em que eles apelam a vários sentidos e são usados pelas crianças como uma espécie de suporte físico numa situação de aprendizagem. Assim sendo, parece relevante equipar as aulas de Matemática com todo um conjunto de materiais manipuláveis (cubos, geoplanos, tangrans, réguas, papel ponteado, ábaco, e tantos outros) feitos pelo professor, pelo aluno ou produzidos comercialmente, em adequação com os problemas a resolver, as ideias a explorar ou estruturados de acordo com determinado conceito matemático. [...] (SILVA; MARTINS, 2000, p. 4).

Portanto, o jogo torna-se uma ferramenta de auxílio para progressão do aprendizado do aluno. De acordo com os Parâmetros Curriculares Nacionais (PCN) [1],

...embora o estudo dos números e das operações seja um tema importante nos currículos do ensino fundamental, constata-se, com frequência, que muitos alunos chegam ao final desse curso com um conhecimento insuficiente dos números, de como eles são utilizados e sem ter desenvolvido uma ampla compreensão dos diferentes significados das operações. Provavelmente isso ocorre em função de uma abordagem inadequada para o tratamento dos números e das operações e à pouca ênfase que tradicionalmente é dada a este assunto. (BRASIL, 1998 pp.95).

\footnotetext{
${ }^{1}$ Disponível em: https://www.ime.usp.br/ativestat
} 
Dessa forma, a atividade desenvolvida neste trabalho promove a interação entre os alunos e o desenvolvimento da compreensão do conteúdo com base em jogos na sala de aula, possibilitando uma oportunidade para os alunos desenvolverem diferentes habilidades e, consequentemente, melhorar o rendimento e a aprovação de tais alunos. Além disso, essa atividade pode preencher lacunas deixadas durante o processo tradicional de ensino.

Vale ressaltar que o estágio possui relevância nos currículos dos Cursos de Licenciatura, uma vez que se constituem oportunidades de vivências específicas da docência, com objeto de pesquisa para se planejar: o papel dos estágios na formação inicial de docência e na crítica da estrutura das universidades e escolas. A partir desse processo, é possível conhecer algumas questões, como as dificuldades que os alunos apresentam, e compartilhar essa experiência com os professores, podendo assim estudar possibilidades para a melhoria do ensino básico e fundamental.

\section{Procedimentos Metodológicos}

O ensino de Probabilidade é recomendado desde os primeiros anos da educação básica, pois os conhecimentos e as habilidades adquiridos, ao longo dos anos contribuem na formação do aluno como cidadão (RICARDO, 2016). A atividade consiste em um jogo chamado "Minitrilha," conforme mencionado anteriormente, aplicada no mês de abril de 2019 em duas turmas distintas do terceiro ano do Ensino Médio do Colégio Estadual Cyriaco Russo de Bandeirantes - PR.

O conteúdo abordado é sobre Probabilidade, e o conteúdo teórico já havia sido ensinado aos alunos em aulas expositivas e tradicionais. Ao aplicar o jogo às turmas, pedimos para que os alunos se dividissem em duplas. Entregamos um papel com a descrição das regras do jogo e com a trilha para cada dupla, exibida na Fig. 1, juntamente com uma moeda e duas pecinhas coloridas de material EVA, representando os jogadores. Em seguida, lemos as regras conjuntamente, explicando passo a passo o procedimento do jogo.

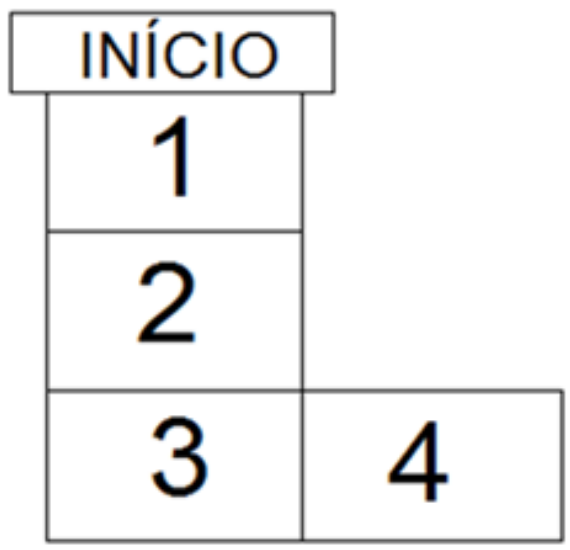

Figura 1: Trilha utilizada no jogo

As regras são descritas a seguir: 
- Duplas: cada jogador da dupla escolhe "cara" ou "coroa" da moeda recebida.

- Ao lançar a moeda, "cara" avança 1 casa; "coroa" avança 2 casas. O jogador que lançou a moeda deve mover sua pecinha.

- Objetivo do jogo é o jogador alcançar ou ultrapassar a casa 4, porém, marca um ponto no placar aquele jogador que escolheu a face obtida no último lançamento da rodada.

- Cada dupla deve repetir a jogada 10 vezes, para que as probabilidades sejam calculadas, e anotar as vitórias no placar da Fig. 2.

\begin{tabular}{|c|c|c|}
\hline $10 x$ & CARA & COROA \\
\hline 1 & & \\
\hline 2 & & \\
\hline 3 & & \\
\hline 4 & & \\
\hline 5 & & \\
\hline 6 & & \\
\hline 7 & & \\
\hline 8 & & \\
\hline 9 & & \\
\hline 10 & & \\
\hline
\end{tabular}

Figura 2: Placar utilizado no jogo

Depois de executadas as 10 rodadas, apresentamos para o cálculo de frequência relativa das ocorrências das faces vencedoras, perguntando para os alunos quem havia vencido o jogo - aquele que escolheu cara ou coroa - com o intuito de que perceba qual é a probabilidade de ganhar. Para isso, escrevemos no quadro a árvore de probabilidades, conforme a Fig. 3. 


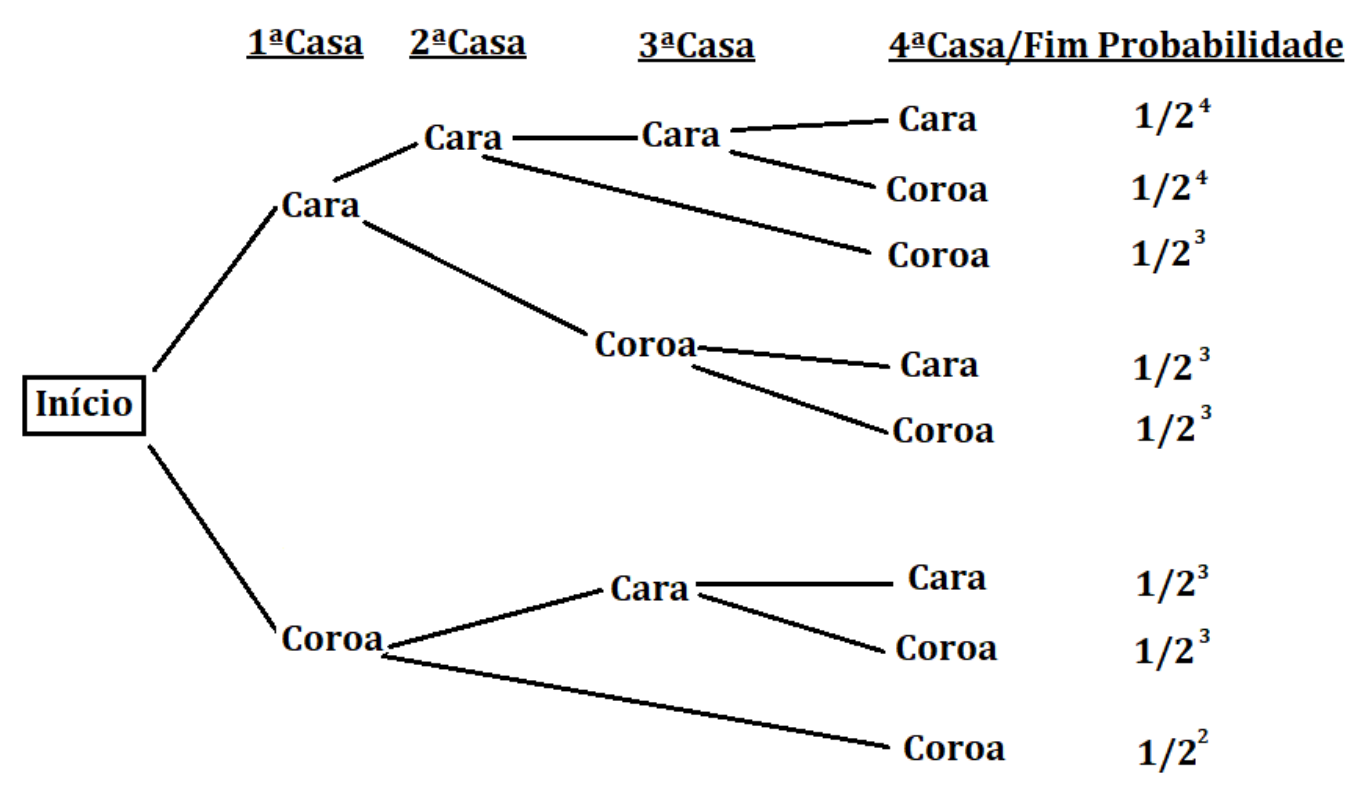

Figura 3: Árvore de probabilidades

A explicação da probabilidade de vitória foi dada conforme todas as possibilidades possíveis, descritas na Fig. 3, somando quais foram as vitórias de cada face da moeda. Para obter a probabilidade de chance de ganhar com cara ou coroa, efetuamos a somatória das duas porcentagens $(0,3125+$ $0,6875=1,0)$ atingindo o número de confiança.

Dessa forma, obtemos:

$$
\begin{gathered}
\mathrm{P}(\text { vitória de cara })=\frac{5}{16}=0,3125 \\
\mathrm{P}(\text { vitória de coroa })=\frac{11}{16}=0,6875,
\end{gathered}
$$

Concluindo, assim, a aplicação do jogo. A atividade, portanto, introduziu os conceitos de Probabilidade e as operações básicas de matemática (adição, subtração, multiplicação e divisão), usando os materiais manipuláveis e o uso de um jogo. Mostramos então, por meio de uma atividade lúdica, uma forma diferente de ensinar matemática, facilitando o aprendizado do discente.

\section{Resultados e Discussões}

Observamos que os alunos desenvolveram-se muito bem no decorrer do jogo, mostrando-se envolvidos e interessados, interagindo bastante uns com os outros. Logo em seguida, quando todos terminaram a décima rodada, explicamos no quadro a árvore de possibilidade de vitória de ter escolhido cara ou coroa e o porquê a opção coroa era a que oferecia mais chance de vitória.

Durante toda a aplicação da atividade, os alunos ficaram atentos e apresentaram um bom desenvolvimento e bastante interesse em aprender e em vencer o jogo. Ao resolver as probabilidades no quadro e somar os termos, todos ajudaram nos cálculos, principalmente com as operações en- 
volvendo frações, respondendo oralmente os resultados de cada uma. Ao questioná-los sobre as possibilidades de calcular o trajeto, os alunos respondiam e interagiam durante toda a aula.

As figuras 4 e 5 exibem o envolvimento dos alunos com a atividade proposta, bem como a folha com as regras do jogo, que lhes foi entregue. Foi pensado em um jogo de execução simples e que ao mesmo tempo introduzisse os conceitos básicos da Probabilidade.

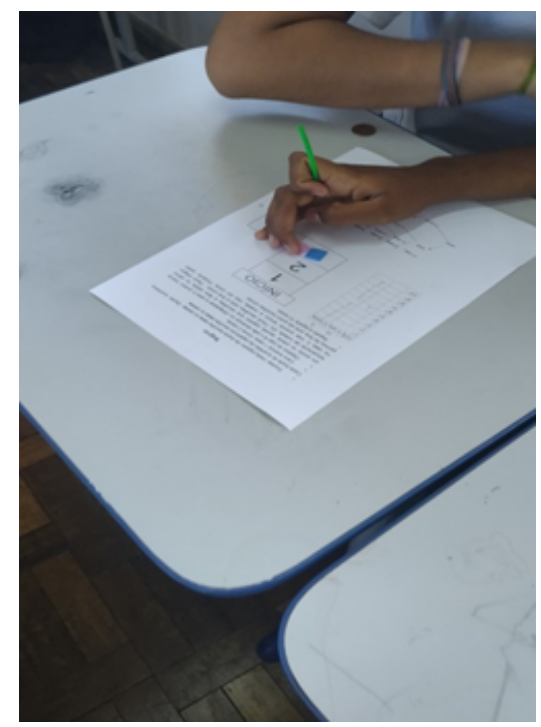

Figura 4: Aplicação da oficina da minitrilha

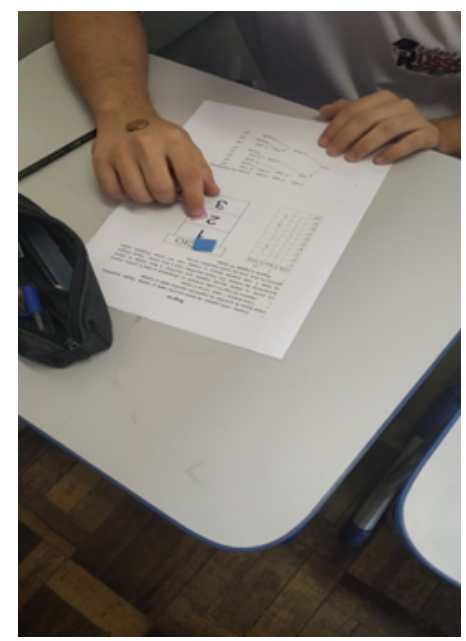

Figura 5: Alunos executando a oficina da minitrilha 
A escolha dessa atividade também ajuda a explicar, além das definições e propriedades do conceito de Probabilidade e as operações básicas de matemática (adição, subtração, multiplicação e divisão), o acaso.

\section{Conclusão}

De fato, a convivência com os discentes na rotina escolar contribuiu para a formação do professor e para seu crescimento profissional e pessoal. Como essa proposta era parte de uma das atividades do Estágio Supervisionado, a estagiária teve a oportunidade de aprender como se portar e agir perante os alunos e como detectar as dificuldades apresentadas por eles, analisando como pode proceder para melhorar o desempenho da turma.

Concluímos que o uso de materiais manipuláveis e jogos para o ensino e aprendizagem de Matemática constitui uma forma eficaz de ensinar matemática, destacando o uso dessa ferramenta pedagógica como estímulo e facilitador de aprendizado do aluno, proporcionando uma oportunidade de despertar novas habilidades e a aquisição do conhecimento por meio de uma atividade lúdica. É importante ressaltar que o jogo proposto neste trabalho foi elaborado considerando o tempo disponível para as aulas de matemática no Ensino Médio e, principalmente, a complexidade da árvore de probabilidades que a trilha pode gerar, de acordo com a Figura 3. Outras variações do jogo, como o aumento do número de casas a serem percorridas, a trilha da Figura 1 pode levar a uma árvore de probabilidades mais complexa e demandar um tempo muito longo para a conclusão da atividade. A forma como a atividade é proposta neste trabalho é possível de ser replicada com tranquilidade em uma aula de matemática do Ensino Médio.

\section{Referências}

[1] Brasil. Ministério da Educação. Secretaria de Educação Fundamental. Parâmetros Curriculares Nacionais: Matemática. Brasília: MEC/SEF, 1998. 148 p.

[2] Lorenzato, S. O Laboratório de ensino de Matemática na formação do professor. Campinas, SP: Autores Associados, 2006. (Coleção formação de professores).

[3] Moura, M. O de. O Jogo e a construção do conhecimento matemático. Série Ideias, São Paulo, n. 10, p. 45-52, 1992.

[4] Muniz, C. A. Brincar e jogar: enlaces teóricos e metodológicos no campo da educação matemática. São Paulo: Autêntica, 2010.

[5] Ricardo, A. C. K. O uso de jogos no ensino de probabilidade na educação básica. Trabalho de conclusão de curso, Universidade Federal de São João del-Rei, 2016.

[6] Silva, A.; Martins, S. ' Falar de Matemática hoje é ...."Millenium - Revista do ISPV: Instituto Superior Politécnico de Viseu, sem, $\mathrm{n}^{\circ}$ 20, out de 2000. Disponível em: http://www.ipv.pt/millenium/20_ect5.htm. Acesso em: 07 jun 2020. 
Thallia Aline Ramos Universidade Tecnológica Federal do Paraná (UTFPR) Câmpus Cornélio Procópio Departamento Acadêmico de Matemática. <thallia@alunos.utfpr.edu.br>

Glaucia Maria Bressan Universidade Tecnológica Federal do Paraná (UTFPR) Câmpus Cornélio Procópio Departamento Acadêmico de Matemática. <glauciabressan@utfpr.edu.br>

Recebido: $09 / 06 / 2020$

Publicado: 26/03/2021 